\title{
A FUNDAMENTAÇÃO EPISTEMOLÓGICA DA BIBLIOGRAFIA ENTRE ROBERT ESTIVALS E JEAN MEYRIAT: NOTAS DE UM DISCURSO FRANCÓFONO
}

\author{
LA FUNDAMENTACIÓN EPISTEMOLÓGICA DE LA \\ BIBLIOGRAFÍA ENTRE ROBERT ESTIVALS Y JEAN \\ MEYRIAT: NOTAS DE UN DISCURSO FRANCÓFONO
}

\author{
Gustavo Silva Saldanhaa \\ Viviane Couzinet ${ }^{\mathrm{b}}$
}

\begin{abstract}
RESUMO
Introdução: O panorama do estudo está na reflexão sobre o lugar da bibliografia na construção da Ciência da Informação no discurso francófono, com foco no pensamento de Robert Estivals e Jean Meyriat, epistemólogos co-fundadores das ciências da informação e comunicação na França. Objetivo: Discutir a construção dos modos de categorização da bibliografia na epistemologia informacional. Nós nos perguntamos aqui, de um modo geral, como a bibliografia é identificada nos discursos epistemológicos da Ciência da Informação $(\mathrm{Cl})$ em sua constituição. Metodologia: Trata-se de um estudo teórico, baseado na reflexão epistemológico-histórica, a partir dos aportes reflexivos de Wilhelm Dilthey e Viviane Couzinet sobre os modos de construção histórica das ciências humanas e sociais e a reflexão meta-metodológica do percurso da institucionalização das disciplinas info-comunicacionais. Resultados: O estudo permite compreender as dinâmicas epistemológico-históricas do conceito de bibliografia entre o século XIX e o século XX, evidenciando o seu papel em diferentes contextos de afirmação epistemológica do campo info-comunicacional, incluindo as abordagens recentes dos anos 1990. Conclusões: As conclusões apontam para a condição epistêmica da bibliografia no espaço-tempo francófono-francês no espelho de Gabriel Peignot, ou seja, a posição deste teórico no início do século XIX tem repercussões diretas nas tardias classificações e representações da bibliografia, como arte, técnica e-ou saber no campo informacional.
\end{abstract}

a Pesquisador Adjunto no IBICT; Docente do Programa de Pós-Graduação em Ciência da Informação-IBICT/UFRJ; Professor Adjunto da UNIRIO; Docente do Programa de PósGraduação em Biblioteconomia na UNIRIO. Email: gustavosaldanha@ibict.br

b Professora da Université Toulouse III Paul Sabatier - Toulouse-França. Email: viviane.couzinet@iut-tlse3.fr 
Descritores: Bibliografia. Epistemologia histórica. Ciência da Informação. Robert Estivals (1927-2016). Jean Meyriat (1921-2010).

\section{INTRODUÇÃO}

A presente reflexão, de fundo epistemológico-histórico, tem como objetivo a discussão da construção dos modos de categorização da bibliografia na epistemologia informacional. Nós nos perguntamos aqui, de um modo geral, como a bibliografia é identificada nos discursos epistemológicos da Ciência da Informação $(\mathrm{Cl})$ em sua constituição.

Para o desenvolvimento da reflexão, nós sustentamos nosso debate no papel de uma epistemologia histórica como construto fundamental para problematizar o percurso de cada campo científico. Esta perspectiva ancorada na historicidade nos permite, ao longo da análise, compreender uma certa luta bibliográfica dentro da própria bibliografia, ou, em outras palavras, um jogo de "traição das imagens", como identificado na problematização da pintura de René Magritte a partir do quadro de mesmo nome, ou, ainda, traição das classificações. Essa condição pode ser compreendida a partir da afirmação da bibliografia como uma técnica na discursividade epistemológico-histórica do campo, ao mesmo tempo em que ela fornece os subsídios para a formalização das próprias classificações que definem a $\mathrm{Cl}$.

Como aporte empírico para a caminhada pela seara epistemológica, nosso foco está na longa tradição epistemológica francesa sobre o discurso bibliográfico. Por isso, perpassamos aqui as visões e as torções iniciais de Gabriel Peignot (1802a, b) e Paul Otlet (1934), reconhecidos e discutidos em razão de ambos representarem fontes reflexivas objetivas, isto é, a partir de suas obras podemos encontrar as "declarações epistêmicas" diretas, ou, ainda, as tentativas de afirmação da cientificidade do campo.

Em seguida, nós discutimos outros dois momentos epistemológicohistóricos igualmente relevantes na construção da $\mathrm{Cl}$ na França, a saber, a questão da bibliografia no tempo da institucionalização epistemológica das 
chamadas Sciences de l'Information et de la Communication. Esse passo nos leva ao "dado empírico" final, ou seja, o modo como Robert Estivals e Jean Meyriat identificam e classificam a bibliografia no contexto da $\mathrm{Cl}$.

A partir deste percurso, podemos compreender a construção do pensamento bibliográfico pós-classificação francesa dos anos 1990 e seu lastro histórico, a saber, suas relações entre passado e presente, por exemplo, entre Gabriel Peignot e a classificação do campo elaborada por Estivals e Meyriat de 1993. Nossas conclusões apontam para a condição da bibliografia no espelho de Peignot, ou seja, a posição deste teórico no início do século XIX tem repercussões diretas nas tardias classificações e representações da bibliografia, como arte, técnica e-ou saber no campo informacional, no cerne do pensamento francófono.

\section{A CONSTRUÇÃO DOS MODOS DE CATEGORIZAÇÃO DA BIBLIOGRAFIA NA EPISTEMOLOGIA INFORMACIONAL: A CAMINHO DO CONTEXTO FRANCÓFONO-FRANCÊS}

A preocupação desta reflexão é localizada nas tensões centrais de uma epistemologia histórica. Trata-se de se perguntar "o que é bibliografia" dentro da história do que hoje tratamos sob a noção de "ciência da informação" ou, no caso francês, ciências da informação e comunicação.

Esse movimento nos levou à noção de epistemologia histórica. A questão básica aqui é: como as ideias atravessam o percurso que vai da sua manifestação linguística como conceito (unidade primária da epistemologia clássica) até seus processos de institucionalização (a epistemologia "emancipada" em formato de cursos, currículos, instituições, títulos).

A bibliografia é um terrível fértil para essa reflexão. Desde o primeiro momento de produção reflexiva dentro do fórum $A$ Arte da Bibliografia, temos percebido que ela está em todos os "lugares comuns" (para usar uma expressão metodológica e teórica da Retórica) do que tratamos por "ciência da informação". E ao mesmo tempo no "lugar-nenhum". É um conceito tão potente que é capaz de jamais se atualizar enquanto tal, enquanto conceito, em tantas 
e quantas abordagens que insistem em não o manifestas, ou silenciá-lo, ou eliminá-lo.

Essa reflexão integra a pesquisa de pós-doutorado, voltada para a construção de teorias e abordagens dos estudos info-comunicacionais franceses a partir dos anos 1960, visa colocar em cena a questão da bibliografia dentro do escopo de um certo discurso francês. O estudo repercute inicialmente a atuação teórica de um dos autores franceses mais influentes no trato e na manipulação do conceito de bibliografia: Gabriel Peignot (1802a,b). Este revolucionário do final do século XVIII será fundamental, a partir do seu Dicionário Sistemático de Bibliologia, publicado em 1802, para a obra (bibliográfica) do teórico e documentalista belga Paul Otlet (1934), bem como atingirá (ou seja, a sua influência será marcante), nas contemporâneas demarcações da atual construção (conceitual e institucional) da noção de "ciência da informação" na França. O olhar peignotiano terá, assim, repercussão em Robert Estivals e Jean Meyriat, os principais interlocutores da reflexão no ponto de vista contemporâneo.

Ambos, Estivals (2000, 1993, 1989) e Meyriat (1993, 1989), permitemnos perceber esse movimento entre a categorização do conceito "bibliografia" e sua emancipação (ou não) dentro do cenário francês após 1960. Esse é o percurso básico do diálogo, com foco em uma epistemologia histórica, ou seja, reconhecer "onde" foi "posicionada" a bibliografia (como manifestação conceitual do significante, a princípio) nos processos de institucionalização do nosso campo na França.

\section{O PAPEL CRÍTICO DA EPISTEMOLOGIA HISTÓRICA}

Com Wilhelm Dilthey (2010) reconhecemos como dado mais imediato para o pensamento em ciências humanas aquilo que o filósofo chama de "vivências". No plano da observação de tais "vivências" reconhecemos o "acontecimento" de uma cientificidade que não estruturada na determinação da natureza. 
Ao lado das ciências naturais, e partindo das tarefas da própria vida, desenvolveu-se por si mesmo e de maneira espontânea um grupo de conhecimentos ligados uns aos outros por meio da comunhão de seu objeto. Tais ciências são a história, as ciências econômica e jurídica e a ciência do Estado, a ciência da religião, o estudo da literatura e da poesia, da arquitetura e da música, das visões de mundo e dos sistemas filosóficos e, por fim, a psicologia. Todas essas ciências descrevem, narram, julgam e formam conceitos e teorias em relação ao mesmo grande fato: a espécie humana. (DILTHEY, 2010, p. 19)

A enunciação de sujeitos pesquisadores e sujeitos pesquisados no âmbito de tais ciências "distintas" aponta para compreensão de uma abrangência vasta segundo a perspectiva diltheyana, reunindo indivíduos, famílias, associações, épocas, movimentos históricos, organizações sociais, sistemas de cultura e todo e qualquer estrato social no âmbito que se convenciona tratar como humanidade.

Em nossa abordagem crítica, a epistemologia histórica nos revela 0 seguinte: a chamada fundamentação da $\mathrm{Cl}$, apresenta-se muitas vezes como "não-histórica" (no sentido diltheyano), na medida em que se atenta menos às contradições presentes na busca por uma delimitação dos saberes orientados para as práticas de organização do conhecimento desde o século XIX, e mais às legitimações institucionais de meados do século passado.

Ladeadas à abordagem diltheyana, a visão a-historicista pode ser definida pela a-pluralidade, pela negação das abrangências múltiplas abertas pelo ponto de vista das vivências. A "realidade humano-histórico-social", segundo as palavras de Dilthey (2010, p. 21), parece escapar dos objetivos centrais da epistemologia informacional (não apenas em seu nascimento). Dedicada à "natureza da informação" (segundo o ponto de vista replicado a partir de Borko (1968)), a Ciência da Informação negligenciou as "vivências" e sua historicidade.

A história produz relatos sobre o trabalho econômico, sobre povoamentos, guerras e fundações dos Estados. Eles preenchem nossa alma com grandes imagens, eles nos ensinam sobre o mundo histórico que nos envolve. Porém, o que nos comove nesses relatos é principalmente aquilo que é inacessível aos sentidos, 0 apenas vivenciável, a partir do 
qual surgiram as ocorrências exteriores, como aquilo que lhes é imanente e ao que elas reagem. (DILTHEY, 2010, p. 23, grifo nosso)

Fundadas na conexão entre vida, expressão e compreensão, as ciências humanas - geisteswissenschaften no léxico alemão diltheyano, realizam-se no e para o mundo histórico, ou seja, nas margens da dupla-reflexividade anteriormente indicada. Neste sentido, a epistemologia das ciências humanas é, em sua condição de nascimento, uma crítica da faculdade do conhecimento, uma metateoria gnosiológica atenta às possibilidades de conhecer o outro.

Essa perspectiva epistemológico-histórica repercute, em nosso olhar, a trajetória da pesquisa de Viviane Couzinet no contexto historiográfico das ciências da informação e da comunicação na França. Trata-se de um modo de perceber o percurso de um dado campo científico a partir de suas experiências em Documentação, de suas formas de mediação e da hibridação desenvolvida a partir da construção social dos saberes.

A partir de seu olhar sobre o percurso histórico das ciências da informação e da comunicação na França, Couzinet (2009, 2008, 2003, 2000) nos permite observar o "coração" de uma epistemologia histórica na $\mathrm{Cl}$ em seu contexto internacional. Em outros termos, nós podemos aqui encontrar a formulação de um método e de um olhar específico para a compreensão da epistemologia histórica propriamente info-comunicacional.

Este exercício teórico desenvolvido por Couzinet demonstra-nos como a institucionalização do campo se dá através de formas de representação, de repertórios, de transmissão dos saberes, a partir de publicações profissionais e científicas, suas formas híbridas, suas diferenciações e o conjunto de metarepresentações constituídas a partir das mesmas. Dentre estas metarepresentações, encontraremos, pois, as bibliografias e seu papel no tecido histórico da constituição do campo info-comunicacional francês. A partir daqui nós podemos observar os embates bibliográficos da própria bibliografia, ou do "jogo de traições" que a imagem bibliográfica nos revela. 


\section{A LUTA BIBLIOGRÁFICA DA BIBLIOGRAFIA (OU A TRAIÇÃO DAS CLASSIFICAÇÕES)}

Em grande medida, em nosso percurso de análise até o momento, o que encontramos é uma espécie de "teoria da traição dos espelhos bibliográficos", ou "traição das classificações (bibliográficas)". Quando nos deparamos com as classificações bibliográficas (fruto de uma teoria histórica da bibliografia), em geral, estamos diante da manifestação de tal tese da traição, que nos remete diretamente à pintura "traição das imagens", de René Magritte. A obra é reconhecida centralmente por conjugar as potencialidades da dança da representação no mundo, partindo da simples identificação de um cachimbo e a inscrição ceci n'est pas une pipe (isto não é um cachimbo).

Em mais de um momento, Magritte nos coloca exatamente na situação delicada e embaraçosa dos limites da classificação. Este é seguramente, em nossa visão, um lugar comum da bibliografia: a traição de sua própria tradição classificatória, o seu "difícil" posicionamento na árvore do conhecimento (esta, tal árvore, tecida por teorias e técnicas justamente bibliográficas).

Em outros termos, ao procurar a bibliografia no lugar de uma macrocategoria epistemológica, ou seja, no lugar de ciência, nas próprias classificações bibliográficas, um dos espelhos da tradição e do pensamento bibliográfico, a bibliografia aparece como subdisciplina ou, simplesmente, desaparece. O seu lugar "tradicional" é de uma "técnica".

Pensando a raiz imagético-conceitual das bibliografias como esquemas mentais, sociais e visuais, ou seja, como imagens do mundo, nós chegamos até esta pretensa teoria das traições bibliográficas. Trata-se, pois, de uma meta-metodologia, ou, de mais um modo de pensar a bibliografia a partir da própria bibliografia. Essa condição da relação entre as imagens e o pensamento bibliográfico é uma das teorias centrais da epistemologia infocomunicacional francesa, desenvolvida por Estivals $(2000,1993,1989)$ e a tradição de pesquisa repercutida na Revue de Bibliologie: schéma et schématisation. Essa abordagem aponta para as noções de schème (formação mental de esquematizações) e de schéma (representação gráfica e material da 
realidade esquematizada) como fundamentais para uma teoria geral da Bibliologia e, logo, da Cl.

Abordemos como exemplo esta relação empírica entre os esquemas e as classificações a partir das visões de Peignot, Dewey, Otlet, Ranganathan e da Biblioteca do Congresso dos Estados Unidos. Ou seja, a partir dos esquemas bibliográficos procuremos aqui a construção do lugar da bibliografia no território epistemológico da $\mathrm{Cl}$.

Em Gabriel Peignot, a bibliografia ocupa a sexta classe geral (uma divisão de 7 grandes disciplinas que definem o pensamento bibliológico), reconhecida como o "conhecimento dos livros". Em Dewey, assim como acontece na Classificação Decimal Universal projetada por Paul Otlet e seus colaboradores, a bibliografia surge como uma classe de Generalidades (a conhecida classe 010 - Bibliografias), indicando apenas o artefato referencial, a obra de referência, resultado da teoria e da classificação bibliográfica. Especificamente, na CDU, encontramos na classe 010 a ideia de Bibliografias e Catálogos.

$\mathrm{Na}$ Colon Classification ranganathaniana, nenhuma categoria primária representa a bibliografia diretamente, ou seja, também aqui ela não é equiparada a nenhuma outra episteme. Seus saberes, métodos, abordagens estarão presentes entre as classes principais Z, 1, 2 e 3 , respetivamente, Generalidades, Universo do Conhecimento, Biblioteconomia e Bibliologia.

No plano da teoria da classificação no mundo soviético, as bibliografias construídas a partir de 1930 e com seus esquemas classificatórios publicados entre 1960 e 1968, resulta em uma classificação com 28 classes, também não enuncia a bibliografia como uma ciência. Os saberes bibliográficos estão dispersos entre as classes principais Ciências filológicas, letras e Literatura de conteúdo enciclopédico.

Por fim, encontramos, uma condição rara na classificação Biblioteca do Congresso dos Estados Unidos: a bibliografia é enunciada aqui como "ciência", ou seja, no plano classificatório, é apresentada como parte das divisões das 
grandes epistemes, encontrando-se na classe Z, chamada Bibliografia e Biblioteconomia.

Se nos permitirmos, ainda, ir em outra classificação de Paul Otlet (1934), ou seja, se partirmos da organização sistemática de seu tratado epistemológico (e não da CDU), a saber, o Traité de Documentation, a noção de bibliografia sequer é enunciada em nenhuma das classes primárias e das classes secundárias.

Nosso percurso reflexivo nos leva, pois, do discurso francófono de Paul Otlet ao discurso francês, ou seja, ao olhar propriamente dito do lastro histórico da bibliografia na França.

\section{A LONGA TRADIÇÃO EPISTEMOLÓGICA FRANCESA SOBRE O DISCURSO BIBLIOGRÁFICO (OU A TRADIÇÃO REVOLUCIONÁRIA DA BIBLIOGRAFIA NA FRANÇA)}

Faz-se necessário um pequeno preâmbulo ao discurso francês sobre o universo bibliográfico. No plano bibliográfico e biblioteconômico propriamente ditos, encontramos vultos como Gabriel Naudé, central para a história mundial de nosso campo.

Aqui, trata-se apenas de demarcar o escopo filosófico, social, histórico e cultural da relevância conferida aos contextos onde o pensamento bibliográfico se insere desde que conhecemos sua condição. Assim, percebe-se o papel que categorias como livro, biblioteca, patrimônio bibliográfico, leitura, leitores possuem relação objetiva com os traços culturais e com fenômenos históricos da vida francesa.

Logo, a produção reflexiva na França sobre o universo bibliográfico é reconhecidamente vasta, indo dos estudos de história do livro aos estudos literários, passando pela sociologia dos livros e suas tecnologias de produção e de reprodução. Para evitar longas revisões, no plano filosófico, podemos lembrar do papel da enunciação de uma corrente filosófica central para a Revolução Francesa, o Enciclopedismo, (co)fundindo-se com o pensamento 
bibliográfico: a manifestação de anseios revolucionários ligada diretamente à publicação de uma obra.

Os modos de classificação, de ordenação, de representação do conhecimento na Encyclopédie são, pois, um exemplo direto dessa tradição. No século XIX encontramos as listas de fontes bibliofílicas de tradição francesa. No plano da história do livro, indicamos aqui, dentre tantos, nomes como Roger Chartier, Lucien Febvre, e um parceiro de Meyriat e Estivals na publicação da obra Les sciences de l'écrit, o historiador Henri-Jean Martin, autor do verbete "História do Livro e bibliologia" dentro da obra.

O próprio Martin nos dá, dentro do trabalho de Estivals (1993) e Meyriat (1993), uma visão que remonta a tradição francesa no contexto bibliográfico: a relação entre Humanismo e erudição e a preocupação com a classificação dos livros, o que seria, em sua visão, a base da bibliografia após a prensa gutenbergiana. Para além deste contexto social e histórico, Martin (1993) também nos apresenta o outro cenário, revolucionário, e sua relação com 0 universo bibliográfico.

Dentro do escopo daquilo que indica como a "revolta das esperanças revolucionárias", Martin (1993, p. 287) aponta como parte direta da Revolução Francesa a presença de bibliotecários e intelectuais do mundo bibliográfico, absolutamente envolvidos na luta à procura da realização da utopia de um saber universal. A revisão de Martin, que passa pelo papel fundamental da Bibliofilia francesa chega até o discurso francês sobre a bibliografia moderna, ou bibliografia especializada, demonstra a longa permanência do discurso bibliográfico na França.

Para o nosso recorte epistemológico-histórico, demarcarmos o papel central das visões e das torções em Gabriel Peignot e Paul Otlet, bem como de Louise-Noëlle Malclès.

- Das visões e as torções iniciais de Gabriel Peignot e Paul Otlet à síntese de Louise-Noëlle Malclès.

Em Gabriel Peignot (1802) encontra-se aquela que nos parece ser uma das primeiras afirmações epistemológicas claras da condição bibliográfica no 
plano das ciências, que influenciará as demais formas de enunciação do conceito "bibliografia" a partir do século XIX. É em seu Dicionário Sistemático de Bibliologia onde essa posição é manifestada, em 1802.

Com Peignot (1802a,b) a bibliografia é reconhecida como uma teoria e uma experiência da aplicação de uma dada ciência, a Bibliologia. Apesar de todo o peso do conceito "bibliografia" dado no olhar peignotiano, principalmente no verbete "Sistemas Bibliográficos", um dos mais extensos do Dicionário,

Sabemos, por sua vez, o poder do enunciado "bibliografia", no plano teórico e no plano aplicado, em Paul Otlet (1934). Neste último, o plano aplicado, o Instituto Internacional de Bibliografia é o sinônimo de uma operacionalização mundial do conceito "bibliografia", tomado como teoria e método de uma revolução política. Logo, o desenvolvimento da perspectiva teórica se dá dentro (e não fora) da noção de "bibliografia". Uma ciência, pois, se estabelece aos poucos aqui. Porém, quando esta ciência é enunciada, sabemos, em 1934, na grande obra de Paul Otlet, o Traité de Documentation, o teórico belga realiza o mesmo movimento teórico de Peignot: submete a bibliografia à Bibliologia, ou à Documentologia, ou, ainda, às Ciências Bibliológicas.

Entre Peignot e Otlet encontramos as possíveis "grandes traições". Com o primeiro, a relevância da bibliografia é colocada no espectro de uma complexa teorização epistemológica, porém a bibliografia resta como uma teoria geral de uma epistemologia chamada Bibliologia. Como Paul Otlet a bibliografia ganha a sua grande teoria geral aplicada, seu enorme, vasto espectro metodológico-institucional. No entanto, em seguida é substituída pelo uso dos termos ligados à noção de documento, como Documentação.

Em Malclès (1967) essas visões, em grande parte, se reproduzem. A bibliografia é entendida como o estudo dos instrumentos de informação. Sua primeira consideração está em apontar para a bibliografia em sua construção histórica a partir dos repertórios de livros desenvolvidos ao longo dos séculos.

Retomando o discurso do historiador Charles-Victor Langlois (18631929), Malclès (1967) aponta como central para a compreensão da bibliografia 
o problema do acesso à produção intelectual e de seu uso. A partir desta apresentação, Malclès (1967) apresenta as diferentes tipologias de bibliografia, atravessando, para tal, o percurso histórico que vai das bibliografias no contexto humanista (século XVI), passando pela época histórica (século XVII), pela época científica (XVIII até 1789), pela época bibliofílica (virada do século XVIII para o XIX), pela época artesanal (de 1810 até 1914) e pela época técnica (ou seja, a partir de 1914).

O percurso cronológico de Malclès (1967) nos leva, ao final, à discussão sobre as bibliografias das bibliografias (um olhar meta-metodológico) do próprio pensar e do fazer bibliográfico. No entanto, não existe aqui uma reflexão epistemológica, ou uma consideração sobre o processo de feitura epistêmica de um certo pensamento bibliográfico.

- A bibliografia no tempo da institucionalização epistemológica francesa (Um olhar a partir da análise história e epistemológica de Jean Meyriat)

No tempo da institucionalização epistemológica francesa das chamadas ciências da informação e comunicação, pois, encontramos já uma visão que coloca a bibliografia como um saber ou conjunto de saberes ou de técnicas ligados à Bibliologia, ou à Documentação.

Com a revisão de Jean Meyriat (1993) dentro da obra Les sciences de l'écrit: encyclopédie internationale de Bibliologie nos anos 1970, o posicionamento epistemológico sobre o campo ainda se encontrava raro. É a partir daqui que Meyriat (1993) busca compreender o lugar da Bibliologia (e não da bibliografia) dentre as chamadas ciências da informação e da comunicação. É em 1972 que esta expressão - sciences de l'information et de la communication - ganha formalização e uma oficialização, adquirindo um comité que se tornaria posteriormente uma sociedade científica.

Nesse contexto, a ampla denominação reúne desde estudos de comunicação de massa às pesquisas em teoria literária, história do livro, da leitura. Ainda em 1972, no âmbito do Centre National de la Recherche 
Scientifique (CNRS), adotar-se-á o termo "Ciência da Informação, Documentação". (MEYRIAT, 1993, p. 330). Tal noção respondia ali, no entanto, especificamente, não ao campo científico, ou à disciplina, mas a uma condição empírica: a base de dados do Institut de l'information scientifique et technique (INIST), órgão do governo francês correspondente ao IBICT no Brasil, que era assim denominada e servia de fonte para pesquisa e atualização do corpo de documentalistas do instituto. (COUZINET, 2000).

No espaço-tempo histórico da institucionalização epistemológica francesa em ciências da informação e comunicação, pois, a bibliografia já não se configura como uma "classe principal", como um conceito que poderia sustentar essa própria institucionalização, como o fizera Paul Otlet cerca de 80 anos atrás, na criação do Instituto Internacional de Bibliografia. O papel bibliográfico está dado como uma noção de técnica descritiva.

Em 1983, de acordo com Meyriat (1993), um grupo de pesquisa constituído por membros da Société Française des Sciences de l'Information et de la Communication e da Société de Bibliologie et Schématisation (SBS) se reuniu para propor uma nova classificação do campo, dada a profusão de terminologias e direções de estudo. Fez-se aqui, pois, uma divisão entre a ciência central, ciências periféricas e ciências conexas.

A ciência central do campo foi considerada a Comunicologia; as ciências periféricas incluiriam os estudos de tecnologia da comunicação e os estudos sociais da informação (como história, economia e direito aplicados ao mundo informacional); as ciências conexas abarcariam as ciências formais no contexto da comunicação e da informação, como as ferramentas eletrônicas de tratamento de dados.

Nesse cenário, a Bibliologia passou a constituir uma sub-disciplina da Comunicologia. E a bibliografia não aparece como centralidade, como um enunciado epistemológico, nosso foco aqui. Afinal, onde foi se posicionar a bibliografia no discurso francês? 
- A fundamentação epistemológica da bibliografia entre Estivals e Meyriat (Um olhar a partir das análises epistemológicas de Robert Estivals)

Aqui já chegamos diretamente ao ponto de nosso debate, ou seja, o pensamento de Robert Estivals (2000, 1993, 1989) e Jean Meyriat (1993, 1989). O resultado dos diálogos de Estivals e Meyriat, no plano histórico que vai da institucionalização à consolidação da formação em Ciência da Informação na França, entre os anos 1970 e 1990, está, como dito, na publicação do livro Les sciences de l'écrit: encyclopédie internationale de Bibliologie. Antes, esse percurso é acompanhado pela construção histórica da Revue de Bibliogie. Na enciclopédia mencionada encontramos a classificação realizada pelos dois teóricos, no início dos anos 1990, ou seja, Classification de la Bibliologie selon R. Estivals et J. Meyriat (1990-1992), que já havia sido manifestada nos debates da Revue.

A análise da classificação demonstra, desde o título, a ausência do papel epistemológico do conceito de bibliografia dentro da visão chamada bibliológica. Na classe principal 1, a classe inaugural de toda a classificação, 0 foco é dado ao conceito "bibliologia". O termo "bibliografia" aparecerá apenas na distribuição decimal no fragmento 1641 Bibliografia Material; e 166 Bibliografia científica; 1661 Sociologia da Bibliografia.

Percebe-se, no olhar sobre a estrutura sistemática da obra, que a Bibliografia, enquanto conceito, teoria ou, mesmo, campo do conhecimento, não é enunciada. O foco recai centralmente sobre a noção de Bibliologia (acompanhando, quase dois séculos depois, o pensamento de Gabriel Peignot em sua relação de posicionamento hierárquico Bibliologia sobre Bibliografia). Esse posicionamento é declarado por Robert Estivals (1993) no verbete História da Bibliologia, onde o autor demarca o pioneirismo conceitual de Peignot no desenvolvimento do campo a partir da noção "bibliologia".

O percurso, porém, sob a obra, nos demonstra o papel da bibliografia, conceito, método ou abordagem, no escopo do que os autores definem como "ciências da escrita" (les sciences de l'écrit). Em outras palavras, o espelho das classificações bibliográficas não nos trai. 
No plano da definição epistemológica da Bibliologia, Estivals (1993, p. 34) recorre ao que trata como "teorização da bibliografia". Em suas palavras,

[...] comme la tehcnique d'écriture, la technique de la bibliographie est passée par plusieurs phases orientées vers la théorisation. La première est d'abord concrète et de nature bibliothéconomique. Elle concerne les dépôts d'archives et les premières grandes bibliothèques. (ESTIVALS, 1993, p. 34)

Estilvals (1993) nos coloca, pois, os exemplos na Antiguidade da aparição dos catálogos em Nínive (entre 668 e 664 a.C.), na Biblioteca de Alexandria (em 300 a.C.), principalmente com a ênfase do trabalho de Calímaco de Cirene (morto em 235 a.C.). Aqui, pois, a bibliografia é reconhecida como racionalidade constituída a partir da aparição dos catálogos na Antiguidade.

A segunda fase, na visão de Estivals (1993), está cobriria todo o período que atravessa o fim da Antiguidade e a Idade Média. Seu foco central está na construção de uma visão biobibliográfica. Em outros termos, trata-se do foco na descrição da vida de autores e a organização das listas de obras dos mesmos. Para Estivals, o modelo dessa era está na obra de Claude Galien (130-210) [Cláudio Galeno], no século 2, chamada De libris propriis liber. Logo, neste contexto, a bibliografia é abordada como uma racionalidade biobibliográfica entre o fim da Antiguidade e o discurso da Cristandade

A terceira fase, para Estivals (1993), compreende ao nascimento e ao desenvolvimento da bibliografia (propriamente dita). Sua demarcação aqui está no contexto pós-revolução tipográfica em Gutenberg.

A terceira fase, na visão de Estivals (1993), corresponde à teorização da bibliografia, que inclui as etapas de: definição da disciplina, determinação de seu objeto de estudo, sua condição dentro de um sistema vasto de outros saberes, sua descrição e sua explicação.

Na história da bibliografia, porém, Estivals (1993), afirmar não constar uma explicação sobre os documentos repertoriados, ou seja, a experiência bibliográfica não teria sido, no entanto, um movimento histórico de crítica dos conteúdos. Esse lugar estaria reservado à própria história das ciências. Esse é o contexto em que Estivals (1993) aponta, no plano epistemológico, como o fez 
Peignot (1802), para a Bibliologia como um campo que, a partir do século XIX, atuaria no complexo crítico das "ciências da escrita" (Les sciences de l'écrit), onde a bibliografia permaneceria, mas como método e técnica, não como abordagem teórica. Em outros termos, é nesse momento em que se afirma, em Estivals (1993), a posição peignotiana da Bibliologia como uma teoria da bibliografia. Assim, a Bibliologia é apresentada como a teoria da bibliografia.

A análise da "maturidade" do pensamento de Meyriat e Estivals nos anos 1990 e seu olhar sobre a noção de "bibliografia" pode ser também observada a partir da ideia de "bibliometria". Percebemos que a enunciação do conceito, feito em Les sciences de l'écrit: encyclopédie internationale de Bibliologie a partir de Robert Estivals (1993), parte das definições de Paul Otlet, tomando a bibliometria como a medida e a quantidade aplicada ao estudo dos livros - ou seja, a estatística dos livros se confunde com a bibliometria.

Para essa análise, Estivals (1993) precisamos recorrer, pois, à noção de "Estatística bibliográfica", ou do conjunto de levantamentos quantitativos sobre o universo dos livros realizado no final do século XVIII. Sem se reportar ao enorme trabalho de Conrad Gesner, inclui-se, pois, na visão de Estivals (1993, p. 68), a "estatística bibliográfica teórico-empírica retrospectiva internacional" e a "estatística bibliográfica teórico-empírica internacional corrente". Sobre a primeira, ou seja, sobre o plano histórico das bibliografias retrospectivas, mais uma vez Estivals (1993) dialoga com o trabalho de levantamento de dados bibliográficos feito por Gabriel Peignot (1802) entre os séculos XV, XVII, XVII e XVIII.

Ainda, Estivals (1993, p. 72) recorre à noção de "bibliometria bibliográfica" para aprofundar o papel da bibliografia no contexto histórico e epistemológico da definição de Bibliologia. O termo comporta duas dimensões: a) o inventário, a descrição e a classificação dos fenômenos gráficos; b) a explicação, ou logos (racionalidade e discurso) do e sobre tal conjunto de fenômenos. A noção (bibliometria bibliográfica) guarda um elemento fundamental para nossa análise epistemológica. 
Estivals (1993, p. 72) considera a bibliometria como uma ponte entre a bibliografia e a bibliologia. Para o teórico, a bibliometria ou a medida da escrita e da comunicação escrita (e não do livro, no léxico estivalsiano) encontra na bibliografia o lugar específico de sua aplicação: ela está dada na quantificação de índices normalizados que estão dentro da bibliografia, dos catálogos. Por sua vez, os resultados obtidos dessa intervenção permitem explicar o pensamento bibliológico, a Bibliologia.

Para além disso, Estivals (1993, p. 72) demonstra que todo o estudo bibliométrico repousa sobre a teoria dos índices considerada como uma aplicação da teoria saussuriana do signo. Em outras palavras, o pensamento de Saussure encontra na longa tradição bibliográfica uma aplicação clara. Ou seja, o índice representa uma manifestação objetiva ou o significante de um valor significado. É necessário, pois, compreender uma teoria e uma técnica bibliográficas dos índices que servirão à bibliometria. Cada categoria de bibliografia, de catálogo, de registros de aquisição, de venda, de empréstimo, permite a realização de estudos bibliométricos.

Assim, das bibliografias gerais às classificações bibliográficas, bem como aos tesauros, permite-nos caminhar através da produção geral do conhecimento, da produção por disciplina, da produção por conceitos, o movimento de criação intelectual, os manuscritos ou impressos. $O$ universo das bibliografias (bibliografia especializada, bibliografia exaustiva, bibliografias seletivas, bibliografias universais, nacionais, regionais) oferece a possibilidade de difundir o movimento da produção intelectual internacional, de cada país, de cada região... Logo, aponta Estivals (1993, p. 73) a bibliometria utiliza a diversidade das bibliografias para realizar suas análises.

Deste modo, a bibliometria bibliográfica, nas palavras de Estivals (1993, p. 75), aparece como o "método específico da bibliometria uma vez que ela repousa sobre a ciência descritiva do livro, a bibliografia".

\section{- O pensamento bibliográfico pós-classificação francesa dos anos 1990: notas reflexivas}


Dentre os elementos que remontam a longa, profunda e intensa história da bibliografia entre os discursos francófonos nós podemos reafirmar o papel da escrita, das classificações, dos impressas, da leitura, das bibliotecas, da bibliometria, do patrimônio bibliográfico.

No discurso francês, fica, pois, clara a manutenção da sustentação de um discurso silencioso (no plano epistemológico) sob as noções de informação, comunicação, documentação a partir da bibliografia, bem como a relação (direta ou complementar, independente do plano epistemológico enunciado) entre a bibliografia e elementos que perpassam o mundo erudito pré-século XVII, o mundo revolucionário do século XIX, o contexto das especializações na virada do século XIX para o XX, envolvendo as tecnologias de produção e de reprodução de artefatos bibliográficos, a análise sociológica da criação bibliográfica, os estudos históricos do livro, da biblioteca e da leitura, a própria história das mentalidades (manifestadas através de registros bibliográficos e instituições bibliográficas, como sociedades literárias, bibliotecas, academias), a história e o conjunto de práticas da práxis do bibliotecário.

\section{A BIBLIOGRAFIA NO ESPELHO DE PEIGNOT: CONSIDERAÇÕES FINAIS}

Dentre as questões centrais dessa reflexão sobre o discurso bibliográfico no discurso francófono, podemos afirmar que.

- Problematizadas algumas posições da noção de bibliografia entre Jean Meyriat e Robert Estivals, podemos perceber que a bibliografia é assumida ora como uma técnica, ora como a imediata aplicação de uma teoria (como a teoria bibliológica). Entretanto, ao mesmo tempo está presente como a marca central das teorizações, das tentativas de afirmação epistemológica no discurso francês relacionado ao mundo do livro.

- A questão da centralidade da bibliografia na epistemologia informacional (o que nós hoje, no mundo, em geral chamamos "ciência da informação") pode ser demonstrada, por exemplo, por sua condição dentro do conceito de "bibliometria bibliográfica";

- As contradições na afirmação epistemológica também aparecem. Por exemplo, mesmo colocada como um domínio aplicado da bibliologia, ou das ciências da informação e da comunicação, ao mesmo tempo, quando mergulhamos nas enunciações da bibliografia dentro do discurso de Meyriat e Estivals, percebemos 
que ora a bibliografia é, de fato, vista como uma técnica, ora surge como uma ciência que é a base para a próprio cientificidade - vide o citado caso da noção de bibliometria, que, como visto, nas palavras de Estivals (1993, p. 75), se ancora em uma "ciência descritiva do livro, a bibliografia"

- Por fim, o espelho do pensamento de Gabriel Peignot no desenvolvimento de um discurso sobre a bibliografia, ao longo dos últimos duzentos anos na França, parece-nos ser um dos mais fortes elementos. O reflexo perpassa tanto a consolidação do pensamento de Paul Otlet e como a afirmação das ciências da informação e da comunicação na França, sob o olhar de Meyriat e Estivals.

Nessa "longa série de traição das imagens", reencontramos, pois, René Magritte. Mais especificamente, relemos a provocação representacional magritteana a partir de duas indagações wittgensteinianas:

- A bibliografia é uma representação ou uma apresentação da árvore do conhecimento?

- Afinal, qual é o lugar da bibliografia dentro da própria condição epistemológico-histórica do pensamento bibliográfico?

Ousamos, ainda com Magritte, uma resposta provisória, ancorada no jogo das traições imagéticas: a bibliografia é a raiz e a estrutura de um castelo epistêmico rachado, hoje tratado como info-comunicacional no discurso francófono-francês; ela permanece enigmaticamente viva e em movimento diante do espelho quebrado das lutas locais e internacionais de demarcação nosso campo científico.

\section{REFERÊNCIAS}

BORKO, H. Information Science: What is it? American Documentation, v. 19, n. 1, p. 3-5, jan. 1968.

COUZINET, V. Transmitir, difundir: formas de institucionalização de uma disciplina. Perspectivas em Ciência da Informação, v. 14, n. especial, p. 518, 2009.

. Réprésenter, répertorier, transmettre: formes d'institutionnalisation d'une discipline. In: Colloque Médiations et Usages des Savoirs et de I'Information: un dialogue France - Brésil. Rio de Janeiro: UFRJ. p. 63-81, 2008. 
. Practiciens de l'information et chercheurs : parcours, terrains et

étayages. Documentalistes-Sciences de I'Information, v. 40, p. 118-125, 2003.

Médiations hybrides: le documentaliste et le chercheur en sciences de l'information, Paris: ADBS, 2000.

DILTHEY, W. A construção do mundo histórico nas ciências humanas. São Paulo: Editora UNESP, 2010.

ESTIVALS, R. (Org.). Les sciences de l'écrit: encyclopédie internationale de Bibliologie. Paris: AIB; Retz, 1993.

ESTIVALS, R. Le vocabulaire de la schématisation: approche d'une méthodologie dialectique de la recherche et de la création. Revue de Bibliologie: schéma et schématisation, n. 30, p. 16-24, 1989.

. Théorie lexicale de la schematisation. Schéma et schématisation: revue de schématologie et de bibliologie, n. 52, p. 5-72, 2000.

MALCLÈS, Louise-Noëlle. La bibliographie. Paris: Presses Universitaires de France, 1967.

MARTIN, Henri-Jean. Histoire du livre et bibliologie. In: ESTIVALS, R. (Org.). Les sciences de l'écrit: encyclopédie internationale de Bibliologie. Paris: AIB; Retz, 1993. p. 287-313.

MEYRIAT, J. La bibliologie parmi les sciences de l'information et de la communication. In.: ESTIVALS, R. (Org.). Les sciences de l'écrit: encyclopédie internationale de Bibliologie. Paris: AIB; Retz, 1993. p. 326-338.

. La place du schéma dans les langages de représentation de l'information. Revue de Bibliologie: schéma et schématisation, n. 30, p. 36-46, 1989.

OTLET, P. Traité de documenatation: le livre sur le livre: théorie et pratique. Bruxelas: Editiones Mundaneum, 1934.

PEIGNOT, G. Dictionnaire raisonné de bibliologie, tomo I. Paris: Chez Villier, 1802a. 1802b.

Dictionnaire raisonné de bibliologie, tomo II. Paris: Chez Villier, 


\title{
EPISTEMOLOGICAL FOUNDATION OF BIBLIOGRAPHY BETWEEN ROBERT ESTIVALS AND JEAN MEYRIAT: NOTES FROM A FRANCOPHONE POINT OF VIEW
}

\begin{abstract}
Introduction: The research discusses the place of the bibliography in the construction of Information Science in French point of view, focusing on the Robert Estivals and Jean Meyriat's thought, epistemologists co-founders of the information and communication sciences in France. Objective: To discuss the construction of bibliographic categorization modes in information epistemology. We here ask ourselves, in general, how the bibliography is identified in the epistemological discourses of Information Science $(\mathrm{Cl})$ in its constitution. Methodology: This is a theoretical study, based on the epistemological-historical reflection, from the contributions of Wilhelm Dilthey and Viviane Couzinet on the historical construction of the human and social sciences and on the meta-methodological reflection on the course of institutionalization of disciplines. Results: The research allows us to understand the epistemological-historical dynamics of the concept of bibliography between the nineteenth and twentieth centuries, highlighting its role in different contexts of epistemological affirmation of the field info-communicational, including the recent approaches of the 1990s. Conclusions: The conclusions point to the epistemic condition of French Bibliography in Gabriel Peignot's mirror, that is, his position in the early nineteenth century has direct repercussions on late classifications and representations of the bibliography, such as art, technique and-or know in the informational field.
\end{abstract}

Descriptors:Bibliography. Historical epistemology. Information Science. Robert Estivals (1927-2016). Jean Meyriat (1921-2010).

\section{LA FUNDAMENTACIÓN EPISTEMOLÓGICA DE LA BIBLIOGRAFÍA ENTRE ROBERT ESTIVALS Y JEAN MEYRIAT: NOTAS DE UN DISCURSO FRANCÓFONO}

\begin{abstract}
RESUMEN
Introducción: El panorama del estudio está en la reflexión sobre el lugar de la bibliografía en la construcción de la Ciencia de la Información en el discurso francófono, con foco en el pensamiento de Robert Estivals y Jean Meyriat, epistemólogos co-fundadores de las ciencias de la información y comunicación en Francia. Objetivo: Discutir la construcción de los modos de categorización de la bibliografía en la epistemología informacional. Nos preguntamos aquí cómo la bibliografía se identifica en los discursos epistemológicos de la Ciencia de la Información $(\mathrm{Cl})$ en su constitución. Metodología: Se trata de un estudio teórico, basado en la reflexión epistemológico-histórica, a partir de los aportes reflexivos de Wilhelm Dilthey y Viviane Couzinet sobre los modos de construcción histórica de las ciencias humanas y sociales y la reflexión meta-metodológica del recorrido de la institucionalización de las instituciones disciplinas info-comunicacionales. Resultados:
\end{abstract}

Inf. Inf., Londrina, v. 23, n. 2, p. 181 - 202, maio/ago. 2018.

http://www.uel.br/revistas/informacao/ 
El estudio permite comprender las dinámicas epistemológico-históricas del concepto de bibliografía entre el siglo XIX y el siglo XX, evidenciando su papel en diferentes contextos de afirmación epistemológica del campo info-comunicacional, incluyendo los abordajes recientes de los años 1990. Conclusiones: Las conclusiones apuntan a la condición epistémica de la bibliografía en el espacio-tiempo francófono-francés en el espejo de Gabriel Peignot, o sea, la posición de este teórico a principios del siglo XIX tiene repercusiones directas en las tardías clasificaciones y representaciones de la bibliografía, como arte, técnica y / o saber en el campo informacional.

Descriptores: Bibliografía. Epistemología histórica. Ciencia de la Información. Robert Estivals (1927-2016). Jean Meyriat (1921-2010).

Recebido: 10.05 .2018

Aceito: 25.08 .2018 